\title{
A STATISTICAL STUDY OF THE RATE OF SKELETAL GROWTH IN JUVENILE DIABETES.
}

\author{
BY
}

\section{M. RABINOWITCH, and ELEANOR V. BAZIN.}

(From the Department of Metabolism, Montreal General Hospital, Canada.)

The results of this study are recorded, not because we are convinced that the findings will apply to a much larger series of cases, but in order that they may be tested by others with similarly available data.

A short time ago Priscilla White ${ }^{1}$, working in Joslin's clinic at Boston, made the interesting observation that children with diabetes tend to be overheight, and suggested a causal relationship between rate of skeletal growth and diabetes. Though height and weight measurements are made as a routine in our clinic for diabetes, we had not observed this. On investigating our cases, however, the above mentioned relationship appeared to hold good. Of seventy-one children, forty were over-height, with respect to their ages on admission to the clinic. An interesting observation was that, taken as a whole, the average rate of growth of these diabetic children after treatment was instituted was less than the normal. From this observation alone, it appeared that whatever the stimulus which produces diabetes in the child may be, it also causes excess skeletal growth. This was further suggested by the fact that when all children were grouped with respect to their heights on admission to our clinic, namely, (a) those who were.over-height, and (b) those who were normal or under-height, the average rate of growth of those of the former group was distinctly less than those of the latter.

It is obvious that in a study involving skeletal growth there are many variables to consider and not all of these are readily controllable. For example, standards of measurement vary. A glance at any two of the available tables, selected at random, is evidence of this fact. An equally important consideration is the magnitude of the number of observations possible in any one clinic. In our clinic, as probably in others, children represent only about five per cent. of the total number of diabetics. Of all the variables, the above mentioned appeared to be of the greatest importance and an attempt was made to overcome them in the following manner :-

In the seventh edition of his book on Diseases of Infancy and Childhood, Holt gives two tables with reference to age-height-weight-sex relationships. One of these is concerned with average net heights and weights of healthy children from birth to four years. The other table records average annual rates of increase of height and weight from five to fifteen years. The reason the writer has selected these data as standard is that they are based upon measurements made by ten different authors. In view of the variability of such a factor as body height, it is reasonable to assume that the values given in such a compilation are more likely to approximate to true averages than those based upon experience from any one source. 
It is obvious that, with the above data, one can by very simple calculations construct a comprehensive table of average heights and weights, and average annual increases for the different age intervals from birth to fifteen years. This was done and the data obtained were accepted as standards for the purpose of this investigation.

As stated above, the series studied was small, consisting of 71 children. This introduces a serious variable. Even if it is assumed that the type of frequency distribution with respect to rate of growth is symmetrical, an arithmetical mean can be accepted as the most probable value of any quantity measured only if the number of observations is large. In order to overcome this difficulty as far as possible, the data were treated statistically; the arithmetical means of the different quantities measured were judged by their probable errors.

The raw data consisted of the following in each case :-

(a) Age of the child on admission to the clinic.

(b) Present age.

(c) Height on admission expressed in terms of inches.

(d) Present height expressed in terms of inches.

(e) Increase of height during period of observation, expressed

(i) in terms of inches, and

(ii) as percentage of normal.

Where fractions of years were involved, in order to approximate true values as closely as possible, the 'expected' heights were calculated from expected monthly increases of growth.

As stated above, of these 71 children, 40 were found to be over-height on admission ; also the average rate of growth of the whole group after treatment was instituted was 82 per cent. of the normal. When, however, the subjects were divided into two groups, namely, $(a)$ those over-height on admission, and (b) those normal or under-height, the respective average rates were $75 \cdot 6$ and 90.8 per cent. In other words, it would appear that though there was a decreased growth rate in the whole group, this decrease was marked amongst the children who were over-height.

It will be noted that the difference between the means (averages) of the two groups was $15 \cdot 2 \%$ Was this difference significant? In order to determine this, calculations were made with respect to the probable error of each mean and the ratio of the difference between the means to the probable error of this difference. The value of the latter ratio was $2 \cdot 2$. In other words, the odds against the occurrence of this difference of $15 \cdot 2 \%$ between the means of the two groups being the result of chance are about $6 \cdot 2$ to 1 .

The above data were shown to Professor Raymond Pearl who was kind enough to make the following observations. "What, if any, evidence have you that non-diabetic children who are over-height do not grow more slowly than non-diabetic children who are normal or under-height, in any given interval during the growth period after observation begins? I should expect that over-height children observed at any moment would, in any given short 
time after that moment, grow at a less rapid rate than normal under-height children. In short, what evidence is there that diabetic children are peculiar in this respect of growth rates in relation to height at the beginning of the observation?" Fortunately the necessary data were available to meet this criticism. At the Ladies' Benevolent Society of Montreal* height and weight measurements are made every three months amongst their children.

In order that the diabetic and non-diabetic data may be comparable, 71 normal children were selected at random and in each case similar information was obtained as about the diabetics. The results of the comparative statistical study are summarized in the accompanying table.

TABLE.

Summary of Comparative S'tatistical Study of Skeletal Growth Rate of Noryal and Diabetic Children.

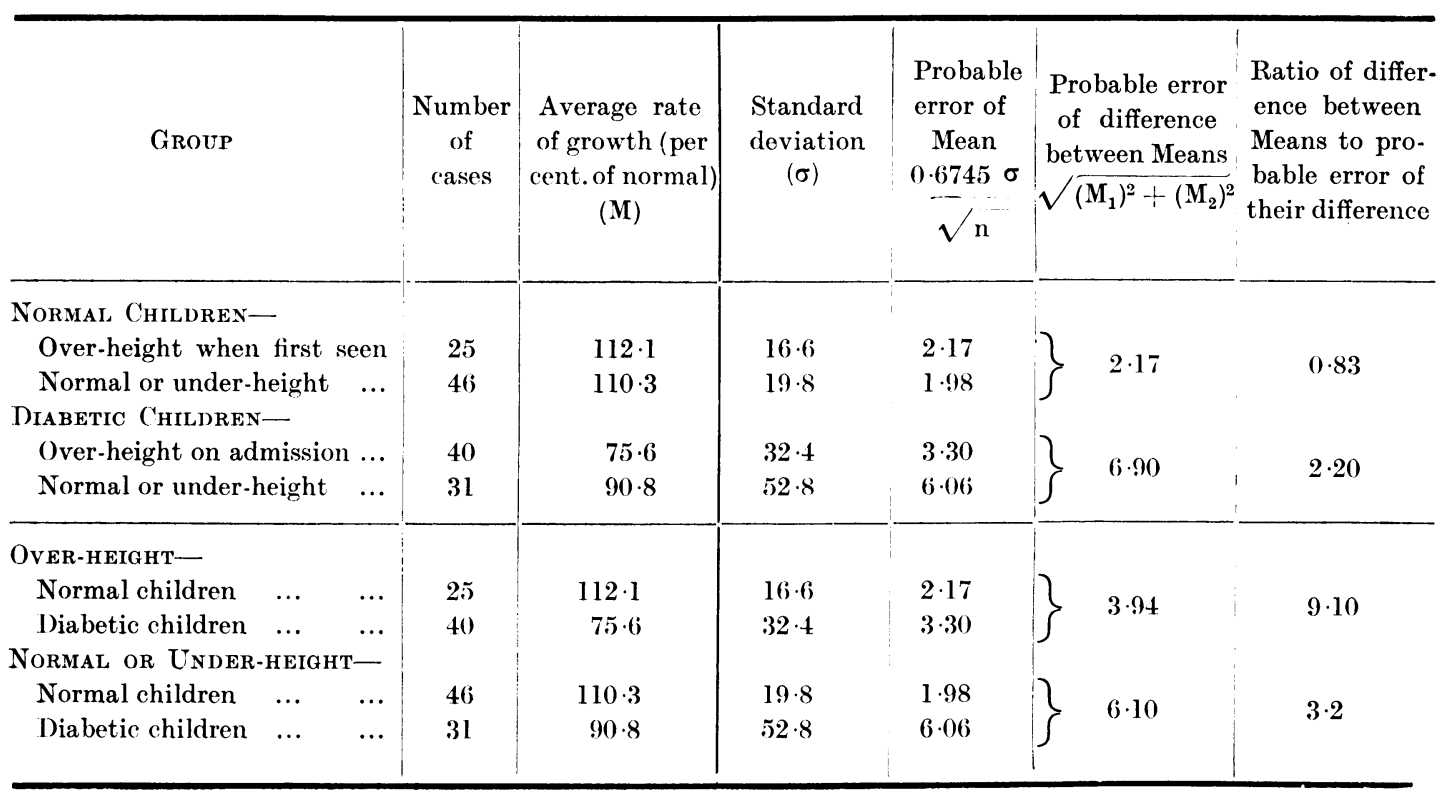

\section{Discussion.}

The data in the table show a definite difference between the average rates of growth of the normal and diabetic children. The normal children who were over-height on admission to the Home of this Society continued to grow more rapidly than the normal, at least during the period of observation. Their average rate of growth was $112 \cdot 1 \%$ of the normal. Of the diabetic children whe were over-height on admission to our clinic, the average rate of growth

* The writers are indebted to Miss G. Towers, Secretary of this Society, who made the data available for study, and to Dr. M. C. C. Childs, its medical officer, who was responsible for the necessary collection and assortment of the data prior to their statistical treatment. 
was only $75 \cdot 6 \%$ of the normal during the period of observation. That the difference between these two means was not accidental may be seen from the ratio of the difference between these means to the probable error of their difference. This was $9 \cdot 1$. In other words, it is practically certain that the difference noted between the diabetic and non-diabetic children was not the result of chance.

Amongst the children who were either normal or under-height, there is also a definite difference between the diabetic and non-diabetic group. It appears that the average rate of growth of the diabetic children after treatment was instituted was less than the normal; whereas, amongst the non-diabetic group it was above the normal. Here, again, there is statistical proof that the difference noted between the means was not the result of chance. The ratio of the difference between the means to the probable error of their difference was $3 \cdot 2$. In other words, the odds against the occurrence of this difference being the result of chance are about 31 to 1 .

The above findings suggest that whatever the stimulus is that causes diabetes in children, it is also responsible for excess skeletal growth. In view of our present knowledge of the relationship between skeletal growth and the anterior lobe of the pituitary gland, and the alleged association between that part of the gland with the sympathetic nervous system, the question arises :Is diabetes, occurring in children who are over-height, of pituitary origin ?* Two important factors must, however, be considered here. First, the conclusion is statistical and does not apply to any particular individual. Secondly, the number of observations which have been made were small. This of necessity has to be so since the number of diabetic children in any one clinic is small. The only purpose of reporting these results, as stated before, is to draw attention to this phenomenon, in order that others with similar available data may repeat the observations made.

It is obvious, in order that the results of future observations may be comparable with our own, the same methods of study must be applied.

\section{REFERENCE.}

1. White, P., J. Am. Med. Ass., Chicago, 1927, LXXXVIII, 170.

\footnotetext{
* Because of this observation, X-ray examinations are now being made as a routine in all of our diabetic children. . Unfortunately, as far as we are aware, exact anthropological measurements of the sella turcica are not on record for comparative purposes. If, however, there is anything in this suggestion, one may find differences between the over-height and under- or normal height diabetic children, or between over-height diabetic and over-height normal uhildren.
} 